\title{
MED12 overexpression is a frequent event in castration-resistant prostate cancer
}

\author{
David Adler1,2,*, Anne Offermann1,2,*, Martin Braun',2, Roopika Menon1,2, \\ Isabella Syring ${ }^{1,2,9}$, Michael Nowak ${ }^{1,2}$, Rebecca Halbach ${ }^{1,2}$, Wenzel Vogel ${ }^{1,2}$, \\ Christian Ruiz ${ }^{3}$, Tobias Zellweger ${ }^{4}$, Cyrill A Rentsch ${ }^{5}$, Maria Svensson ${ }^{6}$, Ove Andren ${ }^{6,7}$, \\ Lukas Bubendorf $^{3}$, Saskia Biskup ${ }^{8}$, Stefan Duensing ${ }^{10}$, Jutta Kirfel $^{2}$ and Sven Perner,2 \\ ${ }^{1}$ Department of Prostate Cancer Research, ${ }^{2}$ Institute of Pathology, University Hospital of Bonn, Sigmund-Freud \\ Strasse 25, 53127 Bonn, Germany \\ ${ }^{3}$ Institute for Pathology, University Hospital Basel, Basel, Switzerland \\ ${ }^{4}$ Department of Urology, St. Claraspital, Basel, Switzerland \\ ${ }^{5}$ Department of Urology, University Hospital Basel, Basel, Switzerland \\ ${ }^{6}$ Department of Urology, University Hospital of Örebro, Örebro, Sweden \\ ${ }^{7}$ School of Health and Medical Sciences, Örebro University, Örebro, Sweden \\ ${ }^{8} \mathrm{Center}$ for Genomics and Transcriptomics, CeGaT GmbH, Tuebingen, Germany \\ ${ }^{9}$ Clinic for Urology and Pediatric Urology, University Hospital of Bonn, Sigmund-Freud Strasse 25, 53127 Bonn, \\ Germany \\ ${ }^{10}$ Section of Molecular Urooncology, Department of Urology, School of Medicine, University of Heidelberg, \\ Heidelberg, Germany \\ *(D Adler and A Offermann contributed equally to this work)
}

\author{
Correspondence \\ should be addressed \\ to $S$ Perner \\ Email \\ sven.perner1972@gmail.com
}

\begin{abstract}
In a recent effort to unravel the molecular basis of prostate cancer (PCa), Barbieri and colleagues using whole-exome sequencing identified a novel recurrently mutated gene, MED12, in $5.4 \%$ of primary PCa. MED12, encoding a subunit of the Mediator complex, is a transducer of $\mathrm{Wnt} / \beta$-catenin signaling, linked to modulation of hedgehog signaling and to the regulation of transforming growth factor beta (TGF $\beta$ )-receptor signaling. Therefore, these studies prompted us to investigate the relevance of MED12 in PCa. Expression of MED12, SMAD3 phosphorylation, and proliferation markers was assessed by immunohistochemistry on tissue microarrays from 633 patients. siRNA-mediated knockdown of MED12 was carried out on PCa cell lines followed by cellular proliferation assays, cell cycle analysis, apoptosis assays, and treatments with recombinant TGF $\beta 3$. We found nuclear overexpression of MED12 in 40\% (28/70) of distant metastatic castration-resistant prostate cancer (CRPC ${ }^{M E T}$ ) and 21\% (19/90) of local-recurrent CRPC (CRPC ${ }^{\mathrm{LOC}}$ ) in comparison with frequencies of less than $11 \%$ in androgen-sensitive $\mathrm{PCa}$, and no overexpression in benign prostatic tissues. MED12 expression was significantly correlated with high proliferative activity in PCa tissues, whereas knockdown of MED12 decreased proliferation, reduced G1- to S-phase transition, and increased the expression of the cell cycle inhibitor p27. TGF $\beta$ signaling activation associates with MED12 nuclear overexpression in tissues and results in a strong increase in MED12 nuclear expression in cell lines. Furthermore, MED12 knockdown
\end{abstract}

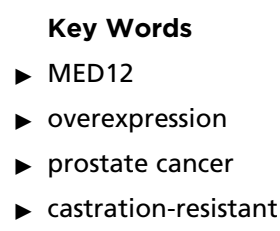

(C) 2014 Society for Endocrinology Printed in Great Britain
Published by Bioscientifica Ltd. 
reduced the expression of the TGF $\beta$ target gene vimentin. Our findings show that MED12 nuclear overexpression is a frequent event in CRPC in comparison with androgen-sensitive $\mathrm{PCa}$ and is directly implicated in TGF $\beta$ signaling.

Endocrine-Related Cancer (2014) 21, 663-675

\section{Introduction}

Prostate cancer (PCa) is a clinically heterogeneous disease and a leading cause of cancer death worldwide, thus unraveling the molecular basis of this disease is of great importance.

Therefore, a notable effort has been made recently by Barbieri et al. (2012) in which new recurrently mutated genes were identified in primary PCa through wholeexome sequencing.

Among the recurrently mutated genes identified, MED12, encoding a subunit of the Mediator complex, is mutated in $5.4 \%$ of primary PCa (Barbieri et al. 2012). Interestingly, in an earlier study, MED12 has been reported to be mutated at a high frequency in uterine leiomyomas (Makinen et al. 2011). MED12 is part of the multi-protein complex Mediator, which is essential for the transcription of protein-coding genes, and serves as hub for diverse signaling pathways (Malik \& Roeder 2010). The division of the Mediator complex into four distinct modules, namely head, middle, tail, and kinase, reflects different functions of distinct Mediator subunits (Cai et al. 2009). MED12 is a subunit of the kinase module and has been shown to function as a transducer of Wnt/B-catenin signaling (Kim et al. 2006), linked to the modulation of hedgehog signaling (Zhou et al. 2006) and to the regulation of transforming growth factor beta (TGF $\beta$ ) receptor signaling (Huang et al. 2012).

TGF $\beta$ signaling regulates prostate growth by inhibiting proliferation and inducing apoptosis, and thus serves as a tumor-suppressor in normal prostatic tissue and early stages of PCa (Tang et al. 1999). Loss or mutations of components of TGF $\beta$ pathway (Tang et al. 1999), as well as altered TGF $\beta$ signaling, promote cell invasion, metastasis, angiogenesis, and epithelial-mesenchymal transition, indicative of an oncogenic role of TGF $\beta$ signaling during prostate tumorigenesis and progression. In addition, activation of TGF $\beta$ signaling has been shown to increase the invasive and migratory behavior of PCa cells (Walker et al. 2013), and inhibition of TGF $\beta$ signaling reduced tumor growth and/or invasiveness in vivo (Gaspar et al. 2007, Moore et al. 2008). Furthermore, a study in 2007 has shown that SMAD-dependent TGF $\beta$ signaling is critical for
PCa growth and progression in nude mice (Lu et al. 2007). The response of metastatic PCa cell lines to TGF $\beta$ depends on the cellular microenvironment. In a recent study, we observed increased proliferation of the PCa cell line PC3 in response to exogenous TGF $\beta 3$ when cells were grown in the presence of all growth factors (Shaikhibrahim et al. 2013). Other studies showed that TGF $\beta$ treatment had no effect upon proliferation in PC3 cells when cells were plated in serum-free medium (Vo et al. 2012).

Prompted by the reports about mutations in MED12 in PCa tissues, and the critical role of MED12 in signaling pathways that have been reported to be involved in PCa (Yardy \& Brewster 2005, Chen et al. 2011), in this study, we investigated the relevance of MED12 in PCa and its relationship with TGF $\beta$ signaling.

\section{Materials and methods}

The study was approved by the Internal Review Board of the University Hospital of Bonn and performed in accordance with the Declaration of Helsinki.

\section{Cohorts}

The study cohort comprised 656 tissue samples, consisting of 40 benign tissue samples, 405 non-metastasized primary PCa samples, 91 lymph node metastasized primary PCa samples or lymph node metastases, and 160 castration-resistant prostate cancer (CRPC) samples (90 local recurrent CRPC and 70 distant metastatic CRPC). These samples were obtained from patients at the University Hospital of Bonn, Basel and Örebro. We collected both primary tumor and corresponding lymph node metastases from 32 patients. We assessed the expression of pSMAD3 in 110 primary $\mathrm{PCa}, 78$ lymph node metastases, and 40 CRPC samples.

\section{Tissue microarrays}

The tissue microarrays were constructed as described previously (Braun et al. 2011).

Published by Bioscientifica Ltd. 


\section{Immunohistochemistry}

The following primary antibodies were used (dilutions, clones, and manufacture): anti-MED12 rabbit polyclonal (1:50, A300-774A, Bethyl Laboratories, Montgomery, TX, USA), anti-PHH3 rabbit polyclonal (1:100, CMC36911010; Cell Marque, Rocklin, CA, USA), ready-to-use anti-Ki-67 rabbit monoclonal $(1: 100,30-9$, Ventana, Tucson, AZ, USA), anti-pSMAD3 rabbit monoclonal (1:50, D12E11, Cell Signaling, Danvers, MA, USA), anti-p27 Kip1 rabbit monoclonal (1:100, D69C12 XP, Cell Signaling), anti-p21 mouse monoclonal (1:100, DCS60.2, Emergo Europe, Hamburg, Germany), and anti-Vimentin rabbit monoclonal (1:100, D21H3, 3932, Cell Signaling) antibody. Negative controls for antibodies were performed using the same immunohistochemistry (IHC) protocol without primary antibody. Protein expression was quantified based on the immunoreactivity score (IRS; Remmele \& Stegner 1987). IRS takes into account both the amount of immunoreactive cells and the intensity of the staining and is calculated as the percentage of immunoreactive tumor cells $(0,0 \% ; 1,<10 \% ; 2,10-50 \% ; 3,51-80 \%$; and $4 \geq 80 \%$ ) $\times$ staining intensity (from 0 , no expression to 3 , strong expression). An IRS with a value of 0 was considered as none or as a very weak expression, whereas an IRS of 1-2 was considered as weak to medium expression. Furthermore, an IRS of 3 and above was considered as high expression (overexpression, IRS $\geq 3$ ). These categories were decided upon before the analyses to avoid the risk of 'data overfitting'. We chose a score of 3 or higher, as it reflects cases which were either visibly expressing MED12 in virtually all cancer cells or harbor at least a marked or strong expression in 11-50\% (or more) of cancer cells. Notably, the statistical correlations were performed with the full-range MED12 IRS and not with the dichotomized categories (i.e. overexpression vs weak-to-medium expression), thus the distinction between overexpressing and nonoverexpressing cases had no effect on these analyses. The association between MED12 and TGF $\beta$ signaling activation was examined dichotomizing the full-range of MED12 IRS in overexpressing and nonoverexpressing cases. For each tissue sample, we analyzed 3 scores and calculated the mean IRS, considering all 3 scores or at least 2 scores excluding outliers.

\section{Cell lines}

All cell lines were purchased from the American Type Culture Collection (ATCC, Manassas, VA, USA) and were grown in a $5 \% \mathrm{CO}_{2}$ incubator at $37^{\circ} \mathrm{C}$ and $85 \%$ humidity. Monolayer cultures of PC3 and BPH1 cells were maintained in RPMI1640 medium (Biochrom, Berlin, Germany) containing 10\% heat-inactivated FCS (Sigma), 1\% streptomycin-penicillin antibiotics (Gibco), and 1\% glutamine. Furthermore, for the cell lines LNCaP and DU145, the medium mentioned earlier was supplemented with $25 \mathrm{mM}$ HEPES buffer (PAA Laboratories GmbH, Pasching, Austria) and 1\% NEAA (Gibco). The cell lines were authenticated using Multiplex Cell Authentication by Multiplexion (Heidelberg, Germany), as described previously (Castro et al. 2013).

\section{Immunofluorescence}

Immunofluorescence (IF) was carried out using antiMED12 rabbit polyclonal antibody (1:50, A300-774A, Bethyl Laboratories) on BPH1, DU145, PC3, and LNCaP cells as described by Cell Signaling Technology, Inc.

\section{siRNA-mediated MED12 knockdown}

For MED12 knockdown, we used SMARTpool-ON-TARGETplus MED12 siRNA (Thermo Scientific, Darmstadt, Germany) and as control, we used ON-TARGETplus nontargeting pool (Thermo Scientific). DU145 and LNCaP were transfected with $100 \mathrm{nmol} / 1$ siRNA using Screenfect A (Genaxxon Bioscience GmbH, Ulm, Germany). The MTT proliferation assay was carried out using siRNA-transfected cells in 96-well plates. For immunocytochemistry (ICC), western blotting analysis, cell cycle analysis, and apoptosis assay, siRNA transfection was carried out in six-well plates; after $72 \mathrm{~h}$, the cells were plated on glass slides for ICC or harvested for protein extraction or functional assays. Quantitative analysis of p27, p21, and Vimentin expression was carried out using Tissue Studio (Definiens Developer XD 2.0, Definiens AG, Munich, Germany).

\section{QRT-PCR}

RNA was isolated using the RNeasy Mini Kit (Qiagen) and reverse transcribed using an iScript cDNA synthesis kit, according to manufacturer's instructions (Bio-Rad).

PCRs were carried out using a Power SYBR Green Kit (Thermo Fisher Scientific) according to the manufacturer's instructions using Light-Cycler 480 II (Roche). For each sample in a given experiment, technical duplicate reactions were carried out using $\beta$-actin as an housekeeping gene. Fold changes were calculated using the formula $2^{-\triangle \Delta C T}$. Primer pairs used for MED12 (Applied Biosystems): MED12: F, 5'-attcaagcagctatgggattcaa- $3^{\prime}$ and MED12: R, 5'-ctggacgaagatcgcgtctg-3'.

Published by Bioscientifica Ltd 


\section{Western blotting}

For the preparation of whole-protein cell lysates, cell pellets were washed with ice-cold PBS and re-suspended in an extraction buffer containing 1\% dithiothreitol, phosphatase inhibitor, protease inhibitor, and the phenylmethanesulfonylfluoride for $60 \mathrm{~min}$. The lysates were then centrifuged for $30 \mathrm{~min}$ at $13000 \mathrm{~g}$ at $4{ }^{\circ} \mathrm{C}$. The supernatant with whole-protein lysate was harvested, and the protein concentration was measured using the bicinchoninic acid-Protein Assay Kit (Thermo Scientific). Thereafter, whole-cell extracts were fractionated by SDSPAGE and transferred to a PVDF membrane using a transfer apparatus according to the manufacturer's protocols (Bio-Rad). After incubation with 5\% nonfat milk in TBST (10 mM Tris, pH 8.0, $150 \mathrm{mM} \mathrm{NaCl}$, and 0.5\% Tween 20) for $30 \mathrm{~min}$, the membrane was incubated with antiMED12 rabbit polyclonal (1:50, A300-774A, Bethyl Laboratories), anti-phospho (S423+S425)-SMAD3 rabbit MAB (1:1000, EP823Y, Abcam, Cambridge, UK), anti$\beta$-actin MAB (1:5000, A1978, Sigma Aldrich, St Louis, MO, USA), and anti-Vimentin rabbit monoclonal (1:1000, 3932 , Cell Signaling) primary antibodies at $4{ }^{\circ} \mathrm{C}$ overnight. The membranes were washed three times with TBST for $10 \mathrm{~min}$ and incubated with a 1:5000 dilution of HRP-conjugated anti-mouse or anti-rabbit antibodies for $1 \mathrm{~h}$. The blots were washed with TBST three times and developed with the ECL System (GE Healthcare Life Science, Freiburg, Germany) according to the manufacturer's protocol.

\section{TGF $\beta$ treatment}

PC3 cells were serum starved in a medium without FCS for $48 \mathrm{~h}$, and then treated with recombinant TGF $\beta 3$ (Immuntools, Friesoythe, Germany) at a concentration of $10 \mathrm{ng} / \mathrm{ml}$ for $1 \mathrm{~h}$, followed by preparation of wholeprotein lysate.

For ICC, PC3 cells were seeded on slides in a medium containing 10\% FCS. When cells were attached, they were grown in serum-free medium for $48 \mathrm{~h}$, and then treated with serum-starved medium with or without $10 \mathrm{ng} / \mathrm{ml}$ TGF $\beta 3$ for 1 or $24 \mathrm{~h}$. The slides were then washed with PBS and cells were fixed in paraformaldehyde (PFA) overnight. For detection of pSMAD3 after $1 \mathrm{~h}$ of TGF $\beta 3$ treatment, ICC was carried out using a primary antibody against pSMAD3. ICC using a primary antibody against MED12 was carried out on 24 h-treated cells. pSMAD3 and MED12 cytoplasmic and nuclear expression were analyzed by two independent pathologists.
For vimentin analysis, PC3 cells treated with scrambled or MED12 siRNA were plated on slides $72 \mathrm{~h}$ after siRNA transfection and grown in a medium containing $10 \%$ FCS and $20 \mathrm{ng} / \mathrm{ml}$ recombinant TGF $\beta 3$ for $48 \mathrm{~h}$. The slides were then washed with PBS and cells were fixed in 4\% PFA overnight. For detection of vimentin, ICC was carried out using a primary antibody against vimentin.

\section{MTT cell proliferation assay}

The cells were analyzed for proliferation using the MTT assays according to the manufacturer's protocol (Roche) after siRNA transfection. DU145 and LNCaP cells were grown in a medium containing $10 \%$ FCS with physiological levels of androgens (1-10 nM dihydrotestosterone). Cellular proliferation was measured 3, 4, and 5 days after siRNA transfection. Each experiment was independently repeated twice in triplicates.

\section{Cell cycle analysis}

For cell cycle analysis, we performed propidium iodide (PI) DNA staining followed by FACS according to standard protocols (Sigma-Aldrich) as well as ICC for cell cycle markers p21 and p27. In more detail, $72 \mathrm{~h}$ (LNCaP cells) or $144 \mathrm{~h}$ (DU145 cells) after siRNA transfection, the cells were harvested and then plated on slides for ICC or used for FACS analysis. For FACS, the cells were washed with ice-cold PBS followed by resuspension in $200 \mu \mathrm{l}$ staining buffer (Tris-buffered saline, Nonidet p-40, 1:1000) containing $7.5 \mathrm{mg} / \mathrm{ml}$ PI (Sigma-Aldrich) and ribonuclease A (Sigma-Aldrich) at a concentration of 1:1000. After 30 min incubation at room temperature, PI staining of cells was analyzed using FACSCanto II Cell Analyzer. FlowJo Software Package (Treestar, OR, USA) was used for analyzing flow cytometry data. For ICC, the cells were grown overnight on slides, washed with PBS, and fixed with PFA. ICC staining was carried out using antibodies against p21 and p27 and analyzed by two independent pathologists.

\section{Annexin V/PI apoptosis assay}

For apoptosis assay, the cells were stained with Annexin V and PI, and evaluated for apoptosis by flow cytometry according to the manufacturer's protocol (eBioscience, San Diego, CA, USA). Briefly, cells were washed twice with PBS and binding buffer, stained with $5 \mu$ l of Annexin V-FITC and $2.5 \mu \mathrm{l}$ of PI in $1 \times$ binding buffer for $15 \mathrm{~min}$

Published by Bioscientifica Ltd 
at room temperature protected from light. Apoptotic cells were determined using FACSCanto II Cell Analyzer. Analysis of apoptotic cells included both, early apoptotic (Annexin V-positive and PI-negative) and late apoptotic (Annexin V-positive and PI-positive) cells.

\section{Statistical analyses}

Statistical analyses were performed using Microsoft Excel 2010 and SPSS 20 (SPSS).

\section{Results}

\section{Nuclear expression and overexpression of MED12 in PCa tissues}

IHC showed that nuclear expression of MED12 was significantly higher in 70 distant metastatic CRPC samples $\left(\mathrm{CRPC}^{\mathrm{MET}}\right.$ ) and 90 local recurrent CRPC samples (CRPC ${ }^{\mathrm{LOC}}$ ) in comparison with androgen-sensitive $\mathrm{PCa}$ and benign prostatic tissues (Fig. 1a and b). Androgen-sensitive PCa consisted of 110 analyzed non-metastasized primary $\mathrm{PCa}\left(\mathrm{PCa}^{\mathrm{NO}}\right)$ as well as 91 lymph-node-metastasized primary $\mathrm{PCa}$ or lymph node metastases $\left(\mathrm{PCa}^{\mathrm{N} 1}\right)$. An independent $\mathrm{PCa}$ validation cohort $\left(\mathrm{PCa}^{\mathrm{VAL}}\right)$, comprising 295 primary PCa tissue samples, was analyzed and included in our results. Nuclear overexpression of MED12 is defined as expression IRS $\geq 3$, and thus MED12 is overexpressed more frequently in CRPC in comparison to androgensensitive PCa (Fig. 1c).

\section{Nuclear expression of MED12 in prostate cell lines}

ICC and IF indicated a medium to strong MED12 nuclear expression in metastatic CRPC cells (PC3 and DU145) and metastatic androgen-sensitive LNCaP cells, compared with medium expression of MED12 in benign prostatic BPH1 cells (Fig. 2a and b).

\section{MED12 effects proliferative activity of PCa cells}

IHC results for the proliferation markers Ki67 and pHH3 were assessed for 110 primary PCa, 91 lymph-nodemetastasized primary $\mathrm{PCa}$ with corresponding lymph node metastases, and 40 CRPC samples. MED12 expression was found to correlate significantly with the expression of

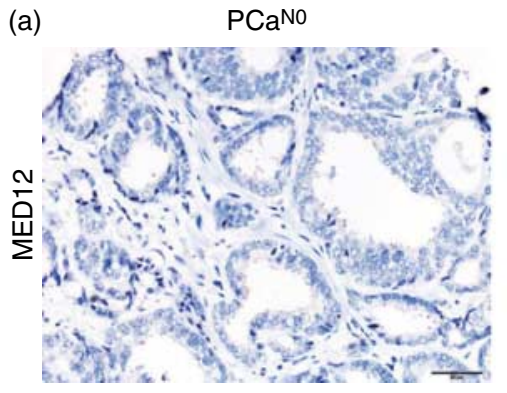

(b)

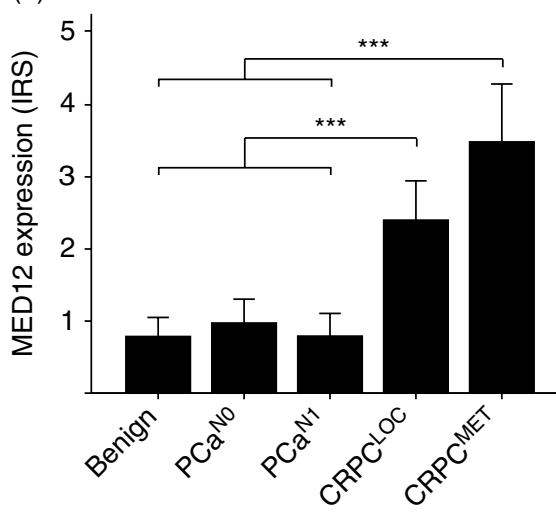

$\mathrm{PCaN1}$

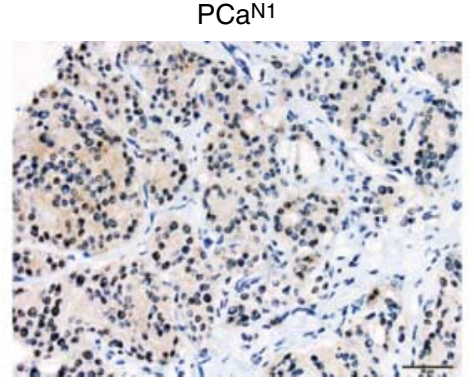

(c)

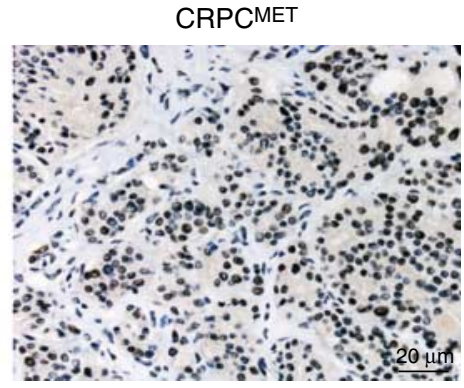

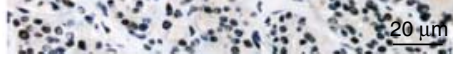

\begin{tabular}{|c|c|}
\hline \multicolumn{2}{|c|}{ Nuclear overexpression (IRS $\geq 3$} \\
\hline & MED12 \\
\hline Benign & $0 \% \quad(0 / 40)$ \\
\hline $\mathrm{PCa}^{\mathrm{NO}}$ & $10 \%(11 / 110)$ \\
\hline PCaVAL & $11 \% \quad(33 / 295)$ \\
\hline $\mathrm{PCa}^{\mathrm{N} 1}$ & $(8 / 91)$ \\
\hline $\mathrm{CRPC}^{\mathrm{LOC}}$ & $(19 / 90)$ \\
\hline $\mathrm{CRPC}^{\mathrm{MET}}$ & $40 \% \quad(28 / 70)$ \\
\hline
\end{tabular}

\section{Figure 1}

MED12 expression in prostate cancer tissue. Immunhistochemical staining of PCa ${ }^{\mathrm{NO}}, \mathrm{PCa}^{\mathrm{N} 1}$, and $\mathrm{CRPC}^{\mathrm{MET}}$ for MED12 (a). Scale bars, $20 \mu \mathrm{m}$. Mean IRS score for MED12 expression in benign, $\mathrm{PCa}^{\mathrm{NO}}, \mathrm{PCa}^{\mathrm{N} 1}$, and $\mathrm{CRPC}^{\mathrm{LOC}}$ and $\mathrm{CRPC}^{\mathrm{MET}}$ respectively (b). Percentage and number of cases with MED12
(C) 2014 Society for Endocrinology Printed in Great Britain nuclear overexpression (defined as expression $\geq$ IRS score 3 ) (c). Bars and error bars indicate mean IRS \pm s.D. Independent $t$-test, $* * * P<0.005$. A full colour version of this figure is available at http://dx.doi.org/10.1530/ ERC-14-0171.

Published by Bioscientifica Ltd. 
(a)
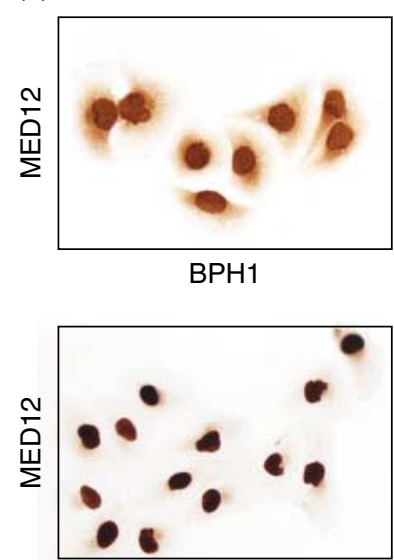

DU145
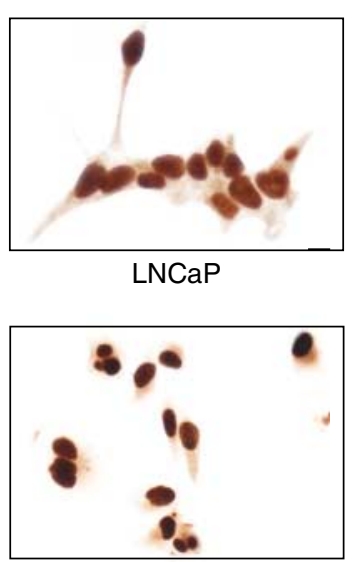

PC3 (b)

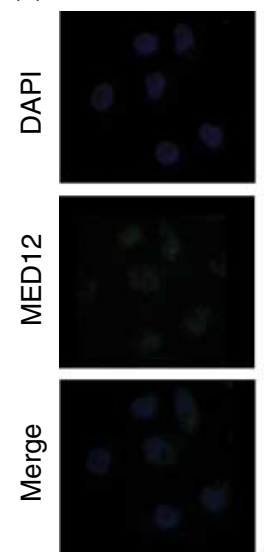

$\mathrm{BPH} 1$
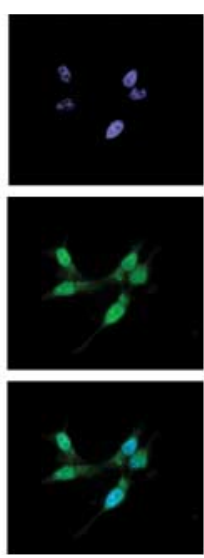

LNCaP
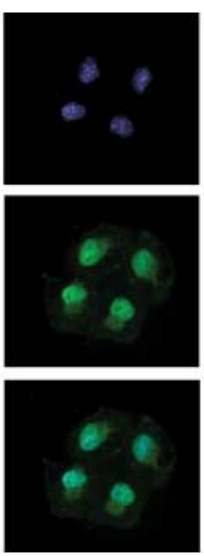

DU145

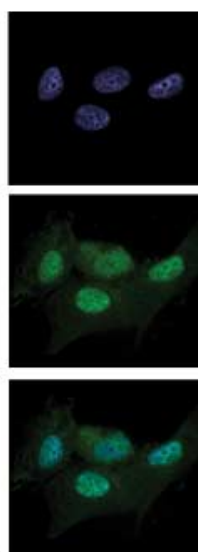

PC3

Figure 2

MED12 expression in prostatic cell lines. Immunocytochemical staining (a) and immunfluorescence (b) of MED12 in benign prostate cell line BPH1 and prostate cancer cell lines LNCaP, DU145, and PC3. A full colour version of this figure is available at http://dx.doi.org/10.1530/ERC-14-0171.

the tumor proliferation markers Ki67 and pHH3 (Pearson correlation, $P<0.01)$.

To assess the effect of MED12 on proliferative activity in PCa cell lines, we carried out siRNA-mediated MED12 knockdown followed by MTT cell proliferation assay. siRNA treatment led to decreased MED12 expression at the mRNA level and protein level in DU145 and LNCaP cells, as illustrated by qRT-PCR and western blotting respectively (Fig. 3a and b). The MTT proliferation assay indicates significantly reduced cell proliferation 5 days after MED12siRNA transfection in both androgen-independent DU145 and androgen-dependent LNCaP cells (Fig. 3c).

\section{Knockdown of MED12 inhibits cell cycle progression in PCa cells}

To assess the effect of MED12 upon cell cycle distribution, we carried out FACS analysis using PI DNA staining in DU145 and LNCaP cells. Cell cycle distribution revealed that DU145 cells with MED12 knockdown accumulated in G0/G1 phase (46\%) in comparison with control cells (11\%), and that the percentage of cells in $\mathrm{G} 2 / \mathrm{M}$ phase was reduced upon MED12 knockdown (17 vs 48\% in control cells) 6 days after siRNA transfection (Fig. 3d). The proportion of LNCaP cells in $\mathrm{S}$ phase of the cell cycle decreased upon MED12 knockdown (9 vs 28\% of control cells), whereas the percentage of cells in G2/M phase increased to 29\% upon MED12 knockdown compared with control cells (11\%) $72 \mathrm{~h}$ after siRNA transfection (Fig. 3e).

We next carried out expression analysis for the cyclindependent kinase inhibitors (CDKi) p21 and p27 in control and MED12-knockdown cells. Immunocytochemical staining revealed increased p27 protein expression and nuclear localization of p27 upon MED12 knockdown in DU145 (Fig. 4a) and LNCaP (Fig. 4b) cells. To quantify the expression of p27 in control and MED12 knockdown cells, we analyzed the immunocytochemical staining intensity (Fig. 4c and d). In DU145 and LNCaP cells with MED12 knockdown, p27 protein expression was increased 2.9and 1.3-fold compared with control cells respectively (Fig. 4c and d). In contrast, DU145 control and MED12 knockdown cells exhibit no difference in p21 protein expression profile (Supplementary Fig. 1a, see section on supplementary data given at the end of this article), whereas p21 is slightly more expressed in LNCaP cells upon MED12 knockdown when compared with control cells (Supplementary Fig. 1b).

\section{MED12 knockdown has no effect upon apoptosis rate in PCa cells}

To examine whether reduced cell proliferation upon MED12 knockdown is a result of increased apoptosis, we carried out Annexin V-PI staining assay. We observed no significant difference in the apoptosis rate between DU145 control (4.2\%) and MED12 knockdown cells (5.9\%) (Supplementary Fig. 2a, see section on supplementary data given at the end of this article). The percentage of apoptotic cells was slightly increased upon MED12 knockdown in LNCaP cells, indicated by $5.7 \%$ Annexin V-positive MED12 knockdown cells compared with $1.8 \%$ Annexin V-positive control cells (Supplementary Fig. 2b).

Published by Bioscientifica Ltd 
(a)

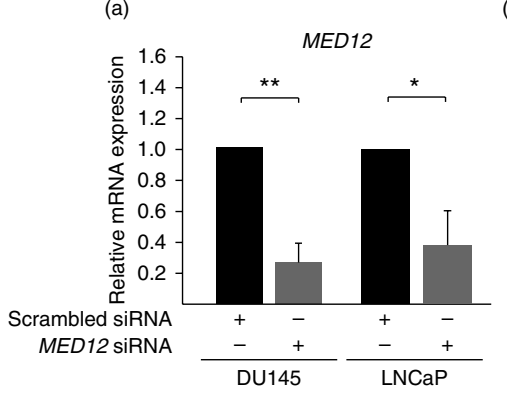

(b)

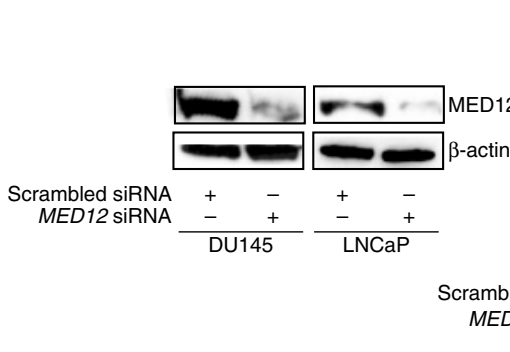

(c)

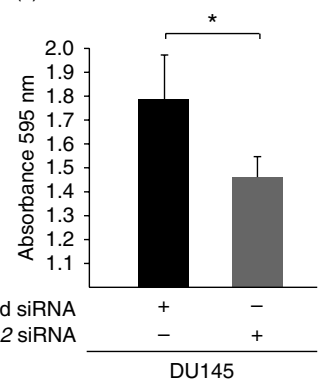

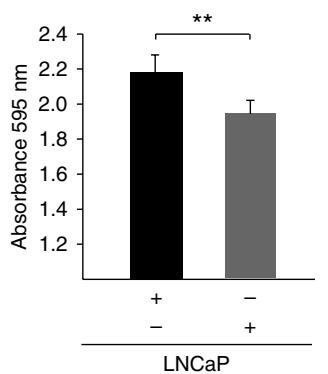

(d)
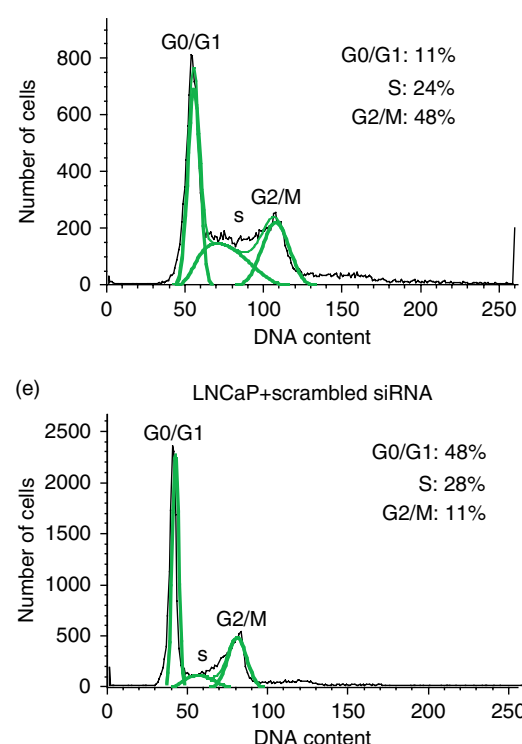
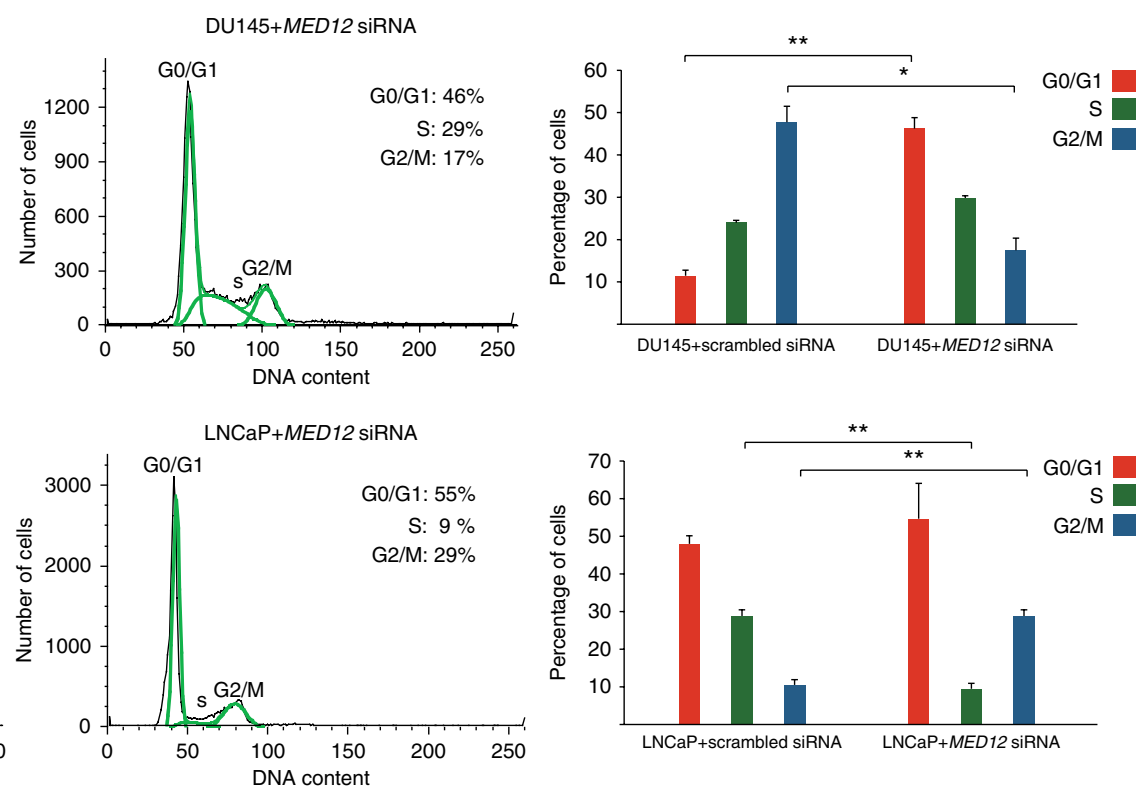

Figure 3

Effect of MED12 upon proliferation and cell cycle distribution in prostate cancer cells. siRNA-mediated MED12 knockdown in DU145 and LNCaP cell lines shows reduced MED12 expression by qRT-PCR (a) and western blotting (b) $72 \mathrm{~h}$ after siRNA transfection. MED12 mRNA expression in cells treated with scrambled siRNA was normalized to one. Reduced proliferation of MED12-knockdown cells compared with cells treated with scrambled siRNA in DU145 and LNCaP cells 5 days after siRNA transfection by MTT proliferation assay (c). Bars and error bars indicate the mean of the absorbance at $595 \mathrm{~nm} \pm$ s.D. The percentages of cells in different phases of the cell cycle are shown for DU145 (d) and LNCaP (e) cells 6 days (DU145) or $72 \mathrm{~h}$ (LNCaP) after transfection with scrambled or MED12-specific siRNA. Bars and error bars indicate mean percentages of cells in each phase \pm s.D. Independent $t$-test, $* P<0.05$ and $* * P<0.01$. A full colour version of this figure is available at http://dx.doi.org/10.1530/ERC-14-0171.

\section{MED12 is implicated in TGF $\beta$ signaling in PCa cells}

In order to examine whether TGF $\beta$ signaling activation is associated with MED12 nuclear overexpression in PCa tissues, we carried out IHC for pSMAD3 on 110 primary PCa, 78 lymph node metastases, and 40 CRPC samples. In contrast to low/absent MED12 expression, MED12 nuclear overexpression was significantly associated with pSMAD3 expression in PCa tissues (Fig. 5a and Supplementary Table 1 , see section on supplementary data given at the end of this article).

To investigate whether TGF $\beta$ signaling activation effects expression and cellular localization of MED12,
PC3 cells were treated with recombinant TGF 33 followed by ICC or MED12. Treatment of PC3 cells with recombinant TGF $\beta 3$ leads to the activation of TGF $\beta$ signaling as indicated by the increased expression and nuclear localization of pSMAD3 (Fig. 5b and c). TGF $\beta$ signaling activation results in a strong increase in MED12 nuclear expression, and a decrease in the cytoplasmic expression (Fig. 5d). Next, we investigated the effect of MED12 on the expression of TGF $\beta$ target genes. ICC (Fig. 5e) as well as western blotting analysis (Fig. 5g) showed reduced Vimentin expression in response to exogenous TGF $\beta 3$ in MED12-knockdown PC3 cells compared with control cells. 
(a)

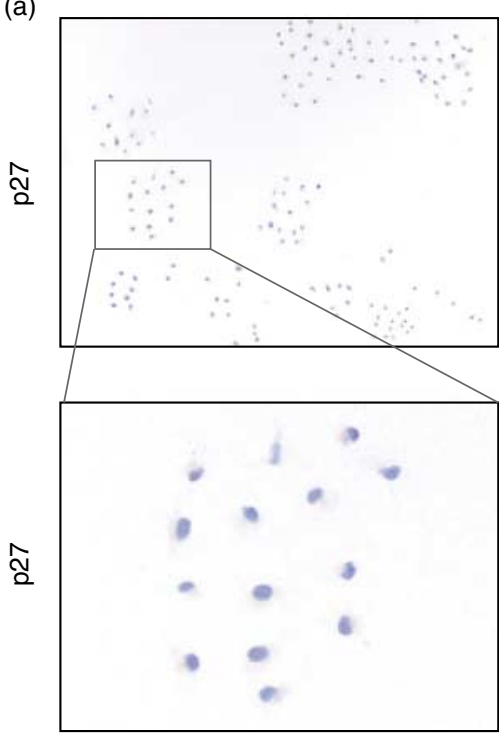

DU145+scrambled siRNA

(b)

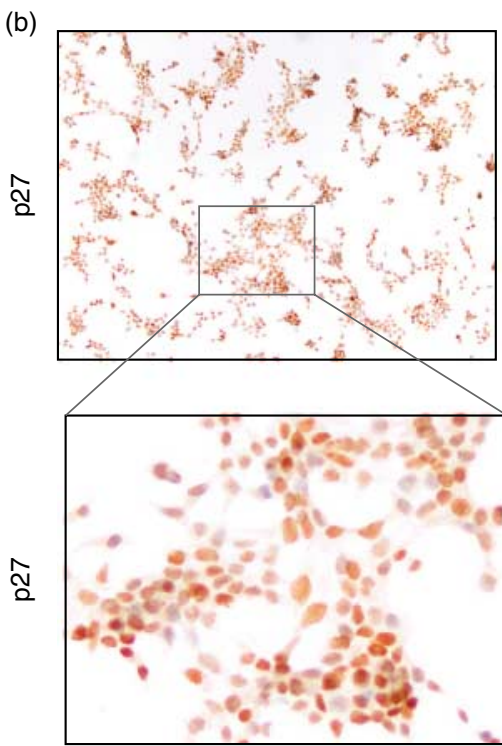

LNCaP+scrambled siRNA

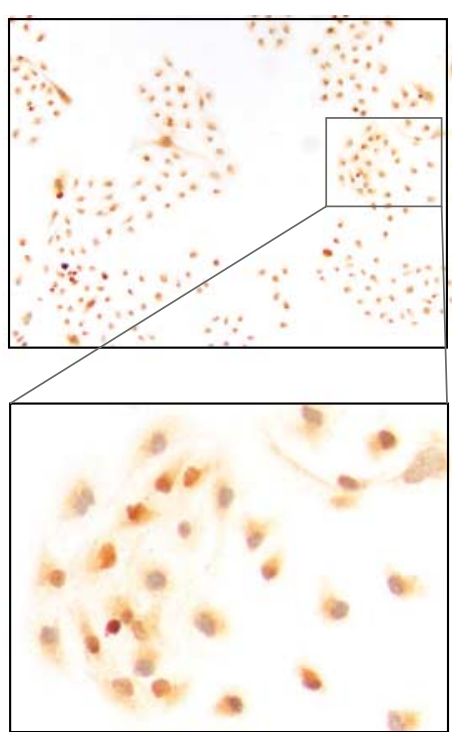

DU145+MED12 siRNA

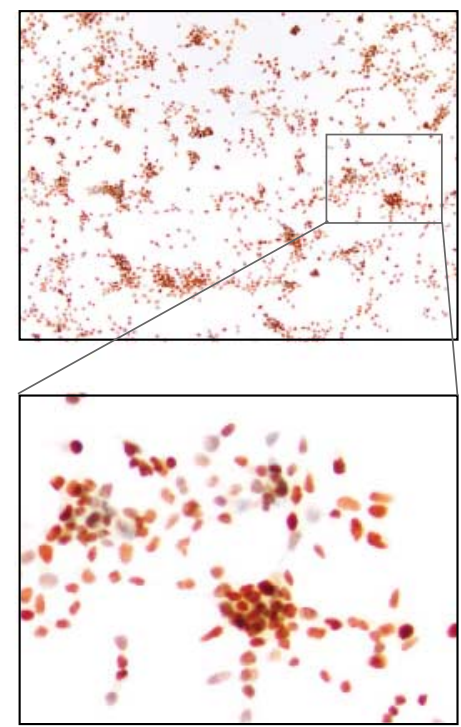

LNCaP+MED12 SiRNA (c)
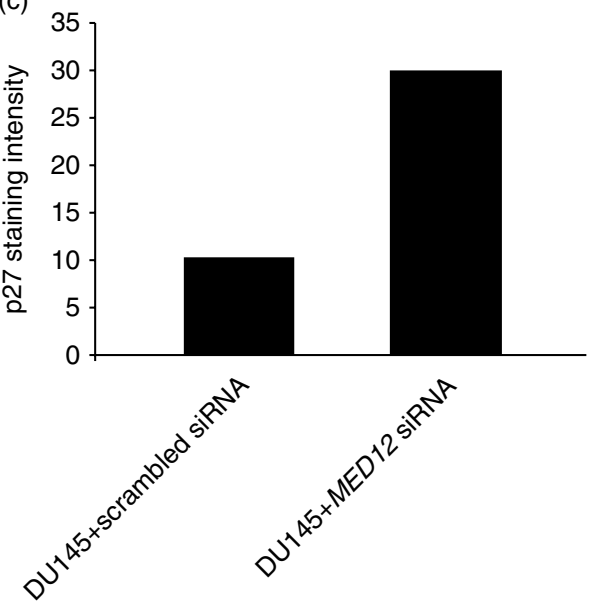

\section{Figure 4}

MED12 knockdown effects p27 protein expression. Immuncytochemical staining ( $a$ and $b$ ) and staining intensity analyses ( $c$ and d) show increased p27 expression in DU145 ( $a$ and $c$ ) and LNCaP (b and d) cells with MED12

Analysis of the immunocytochemical staining intensity revealed that control cells expressed twofold higher Vimentin levels compared with MED12 knockdown cells (Fig. 5f).

\section{Discussion}

In our study, we found MED12 nuclear expression to be significantly higher in distant metastatic CRPC (CRPC $\left.{ }^{\mathrm{MET}}\right)$ knockdown compared with control cells. A full colour version of this figure is available at http://dx.doi.org/10.1530/ERC-14-0171.

and local recurrent CRPC $\left(\mathrm{CRPC}^{\mathrm{LOC}}\right)$ as compared with androgen-sensitive $\mathrm{PCa}$ and benign prostatic tissues (Fig. 1a and b). MED12 was overexpressed in 40\% of $\mathrm{CRPC}^{\mathrm{MET}}$ and $21 \% \mathrm{CRPC}^{\mathrm{LOC}}$ (Fig. 1c).

In the majority of cases, we observed a heterogeneous expression pattern for MED12 within the samples from single patients of primary PCa and lymph node metastases. The focal heterogeneity in staining profiles concerned both, the amount of immunoreactive cells as well 
(a)

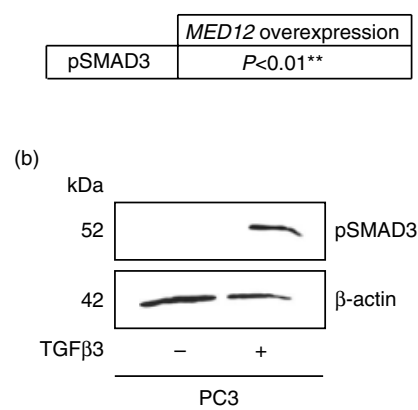

(e)

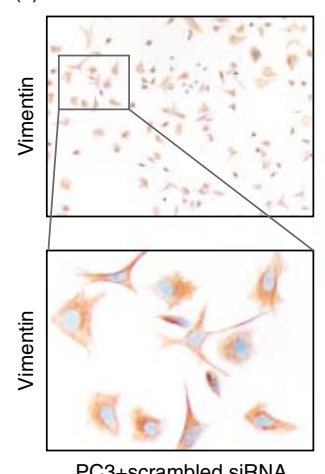

PC3+scrambled siRNA (c)

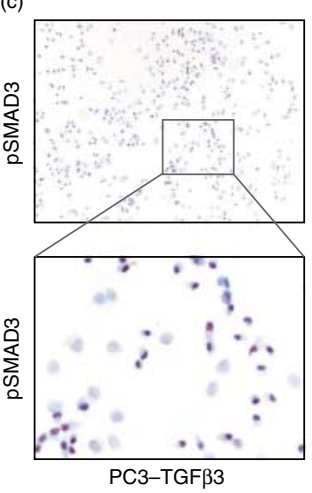

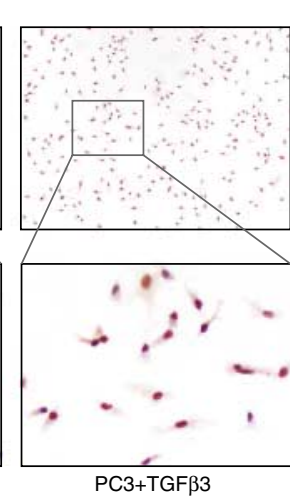

(d)

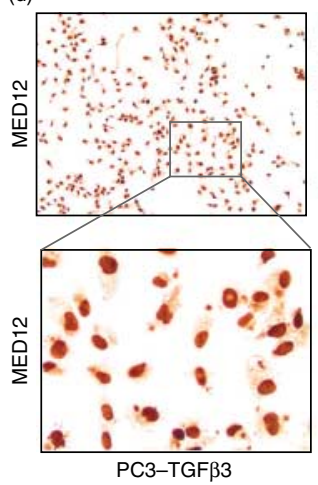

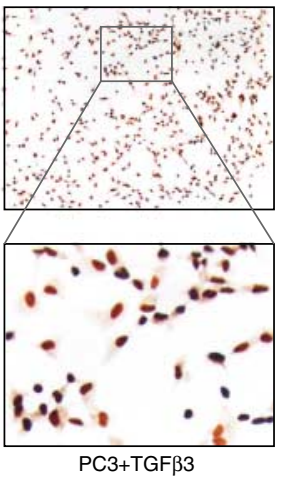

(f)

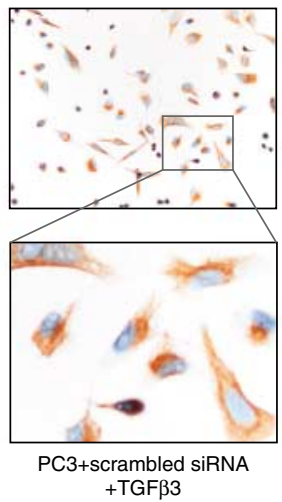

+TGF $\beta 3$

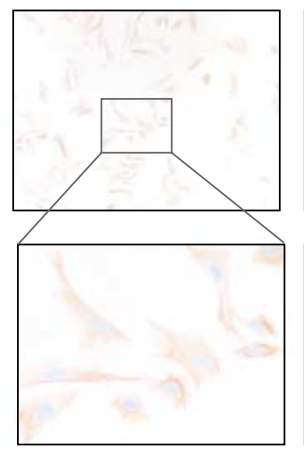

PC3+MED12 SiRNA

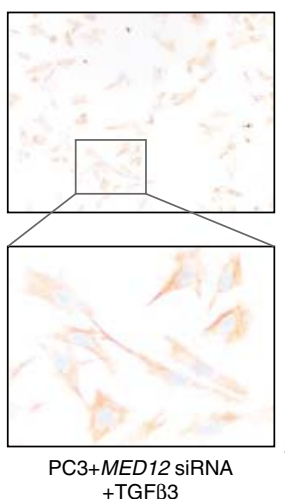

+TGF $\beta 3$

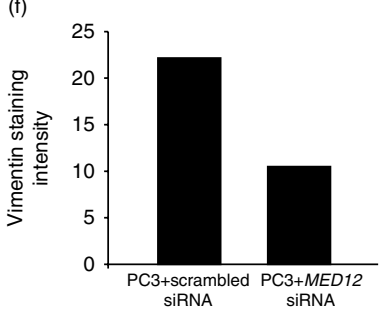

(g) $\mathrm{kD}$

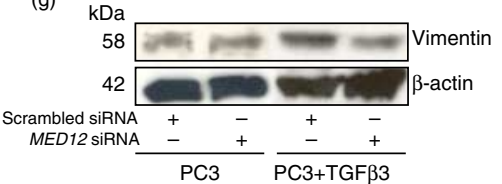

Figure $\mathbf{5}$

MED12 is implicated in TGF $\beta$ signaling. Expression of pSMAD3 is associated significantly with MED12 nuclear overexpression in PCa tissues (a). $\chi^{2}$, $* * P<0.01$. Phosphorylation of SMAD3 in PC3 cells following treatment with $10 \mathrm{ng} / \mathrm{ml}$ recombinant TGF $\beta 3$ shown by western blotting (b). Immunocytochemical staining showed increased PSMAD3 after $1 \mathrm{~h}(\mathrm{c})$ and increased expression and nuclear localization of MED12 (d) in PC3 cells treated with TGF $\beta$ for 24 h compared with untreated cells. Immunocytochemical staining (e) showed reduced vimentin expression in PC3 cells with MED12

as the intensity of the staining. This result may be due to the known heterogeneous and multifocal nature of PCa (Karavitakis et al. 2011). Interestingly, MED12 expression was more homogeneous in CRPC tissues compared with primary PCa and lymph node metastasis. The reduced heterogeneity of MED12 expression in advanced stages may be indicative of an important role of MED12 in the progression of PCa to castration resistance.

In light of our findings from tissue samples, we examined the expression of MED12 in benign prostatic BPH1 as well as metastatic androgen-sensitive LNCaP cells and PCa cells with dispensed androgen signaling (PC3 and DU145). In support of our findings from tissue samples, we found that MED12 exhibits medium to strong nuclear expression in PCa cells, compared with medium expression in benign prostatic cells (Fig. 2a and b). As MED12 is part of the Mediator complex, a co-activator of knockdown compared with control cells grown in a medium with or without $20 \mathrm{ng} / \mathrm{ml}$ recombinant TGF $\beta 3$ for $48 \mathrm{~h}$. Bar graph shows reduced vimentin staining intensity in MED12-knockdown cells compared with control cells (f). Western blotting analysis revealed reduced vimentin expression in PC3 cells with MED12-knockdown compared with control cells grown in medium with or without $20 \mathrm{ng} / \mathrm{ml}$ recombinant TGF $\beta 3$ for $48 \mathrm{~h}$ (g). A full colour version of this figure is available at http://dx.doi.org/10.1530/ ERC-14-0171.

the general transcription machinery (Malik \& Roeder 2010), it is expressed in nonmalignant cells. Consistent with that, we observed a weak staining for MED12 in benign prostate tissues (Fig. 1a and b).

Our observation that MED12 nuclear overexpression is a frequent event in CRPC in comparison with androgensensitive PCa, prompted us to examine whether MED12 expression was correlated with high proliferative activity in PCa. MED12 expression correlated significantly with the proliferation markers Ki67 and pHH3 in PCa tissues. Based upon these results, we found that knockdown of MED12 decreased proliferation in both androgen-independent CRPC DU145 cells and androgen-dependent LNCaP cells (Fig. $3 b$ and c). In order to examine whether the reduced proliferation of MED12-knockdown cells may be affected by cell cycle arrest and/or increased apoptosis, we carried out cell cycle assays as well as apoptosis assays in DU145 and

Published by Bioscientifica Ltd 
LNCaP cells. While we found no effect of MED12 knockdown upon the percentage of apoptotic cells (Supplementary Fig. 2), we observed significant differences in the cell cycle distribution between control and MED12-knockdown DU145 and LNCaP cells (Fig. 3d and e). In DU145 cells, we found that MED12-knockdown cells being significantly arrested in G0/G1 phase (Fig. 3d), and in LNCaP cells we observed that the percentage of cells in S phase was reduced upon MED12 knockdown (Fig. 3e). These results are indicative of a role of MED12 in the G1to S-phase transition. To get further support for MED12knockdown-induced cell cycle arrest at G0/G1 phase, we analyzed the expression levels of G1- to S-phase negative regulators $\mathrm{p} 21$ and $\mathrm{p} 27$. These proteins are able to block the kinase activity of CDKs at the G1- to S-phase checkpoint during cell cycle, and their upregulation has been shown to cause growth inhibition (Sherr \& Roberts 1999). At the same time, reduced p27 expression has been associated with a more aggressive phenotype and poor survival (Doganavsargil et al. 2006). Increased p27 expression in MED12-knockdown DU145 and LNCaP cells (Fig. 4a and b) may provide evidence that MED12 is a negative regulator of p27 expression, which is consistent with the observation that MED12-knockdown cells showed reduced proliferation in MTT assays and decreased G1- to S-phase transition in cell cycle analysis. Differences in p21 expression upon MED12 knockdown were only slightly detectable in LNCaP cells (Supplementary Fig. 1b), and could not been observed in DU145 cells (Supplementary Fig. 1a). However, studies uncovered important differences between several cell types with regard to the regulation of CDK inhibitors such as p21 and p27 (Sherr \& Roberts 1999) which could explain our different results in DU145 and LNCaP cells for p21 expression. Furthermore, several reports indicate that p21 and p27 have different functions (Martin-Caballero et al. 2004, Munoz-Alonso et al. 2005), and can be differentially expressed in cancer cells (Sherr \& Roberts 1999). Interestingly, MED12 knockdown may affect signaling pathways, including $\beta$-catenin signaling, whose inhibition has been shown to cause G1 arrest in colorectal cancer cells (van de Wetering et al. 2002). In addition to reduced G1- to S-phase transition in MED12-knockdown cells, in LNCaP cells we observed that the percentage of cells in G2/M phase was increased upon MED12 knockdown (Fig. 3e). Notably, we found MED12 expression in PCa tissues was correlated with the expression of the M-phase marker pHH3, which is upregulated during G2- to M-phase transition (Hesse et al. 2012). Together with our results indicating that LNCaP cells with MED12 knockdown exhibited reduced cell viability by MTT assay, we propose that MED12 may be involved in the checkpoint regulation during G2- to M-phase transition. Interestingly, in malignant melanoma cells, the loss of CDK8 activity, which requires MED12 (Knuesel et al. 2009), reduced proliferation mediated by $\mathrm{G} 2 / \mathrm{M}$-phase arrest (Kapoor et al. 2010). Previous studies revealed fundamental differences in cell cycle regulator patterns between LNCaP and DU145 cells, and specific cell-cycle-regulating pathways in the two cell lines (Mad'arova et al. 2002, Cifuentes et al. 2003, Benavides et al. 2010). Results from studies indicated that the androgen receptor and p53 status might determine different responses to CDK inhibitors and cell-cycle-modulating agents between LNCaP and DU145 cells (Mad'arova et al. 2002, Benavides et al. 2010). Our results show different effects of MED12 knockdown upon cell cycle regulation in LNCaP and DU145 cells, and may support previous observations described earlier. Further experiments are needed to unravel the molecular basis of MED12-mediated cell cycle regulation.

Recent studies have reported that SMAD3 is overexpressed in PCa tissues and is necessary for progressive growth of PCa cells in nude mice (Lu et al. 2007). On the basis of these results and results from other studies showing that MED12 is implicated in TGF $\beta$-receptor regulation (Huang et al. 2012) and our findings that MED12 has increased expressed in castration-resistant PCa tissues, we aimed to investigate whether MED12 is implicated in TGF $\beta$ signaling in PCa. We found that the activation of TGF $\beta$ signaling was associated with MED12 nuclear overexpression in PCa tissue (Fig. 5a and Supplementary Table 1). Results of recent studies have indicated that the TGF $\beta$ isoform 3 is highly expressed in PCa and androgenindependent PCa cells (Karan et al. 2002). Furthermore, TGF $\beta 3$ is more potent in increasing motility and invasive behavior in PCa cells (Walker et al. 2013), as well as in endometrial cancer cells compared with other isoforms (Van Themsche et al. 2007). Therefore, we used TGF $\beta 3$ to activate TGF $\beta$ signaling in PC3 cells and found a strong increase in MED12 nuclear expression and a decrease in the cytoplasmic expression (Fig. 5d). Our observations indicate that the nuclear MED12 overexpression is a response to the activation of TGF $\beta$ signaling in PCa.

Based on these observations, we aimed to investigate the role of MED12 in TGF $\beta$-regulated gene expression. TGF $\beta$ signaling activation leads to increased expression of vimentin, a crucial event during PCa progression and metastasis (Zavadil \& Bottinger 2005). We observed reduced Vimentin expression in PC3 cells with MED12 knockdown grown under TGF $\beta 3$ stimulation, when compared with control cells (Fig. 5e and f). We suggest that MED12, as part of the Mediator complex, is required

Published by Bioscientifica Ltd. 
for TGF $\beta$-regulated gene expression, and that MED12 is therefore shuttled into the nucleus in response to TGF $\beta$ signaling activation. Recently, a study by Huang and colleagues revealed that MED12 has an additional function in the cytoplasm distinct from its role within the Mediator complex, and there it negatively regulates TGF $\beta$ receptor signaling. In contrast, the aim of our study was to investigate the role of MED12 as part of the Mediator complex, which acts in the nucleus as a co-activator for the transcription machinery. In addition, Huang et al. (2012) carried out MED12 knockdown experiments under conditions without activation of TGF $\beta$ signaling. In contrast, we investigated the effect of MED12 knockdown upon TGF $\beta$ signaling in response to TGF $\beta$ pathway activation.

However, further studies are required to investigate the underlying mechanisms. It has to be considered that p27 is also a TGF $\beta$-responsive gene in prostate cell lines (Robson et al. 1999), and that TGF $\beta$-regulated p27 expression leads to growth inhibition in different cell lines (Polyak et al. 1994). Interestingly, recent studies have demonstrated DU145 cells to be refractory to growth arrest by TGF $\beta$ (Cipriano \& Chen 1998), and that TGF $\beta$ treatment of DU145 cells led to increased p21 expression, but had no effect on p27 expression (Park et al. 2000). Furthermore, several studies have reported that LNCaP cells are insensitive to activation of TGF $\beta$ signaling (Zhang et al. 2005), thus DU145 and LNCaP cells have been described as being insensitive to TGF $\beta$-regulated p27 expression. In this study, we found increased p27 expression in MED12-knockdown DU145 and LNCaP cells and decreased Vimentin expression in MED12-knockdown PC3 cells.

Recently, we have found similar expression patterns in PCa tissues and functional results in cell lines for the Mediator tail subunit MED15 (Shaikhibrahim et al. 2013). The interplay between different subunits of the Mediator complex provides the basis for the function of the Mediator as a hub between signaling pathways and the transcription of specific genes. Concordantly, studies showed that the simultaneous inactivation of multiple Mediator subunits has different effects compared with single knockdown of individual subunits (Larsson et al. 2013). In addition, some subunits require the activity of other subunits of the Mediator for specific signaling (Knuesel et al. 2009). Therefore, it is likely that a simultaneous upregulation of MED12 and MED15 is required for the activation of pathways and the expression of specific genes. Interestingly, in PCa tissues, we found that MED12 overexpression only occurs when MED15 is overexpressed (data not shown). This result may provide evidence that higher MED15 expression levels lead directly or indirectly to higher MED12 expression. Further experiments are needed to explore whether the activity of specific subunits influences the expression of other Mediator subunits, or whether the activation of specific pathways may lead to the simultaneous upregulation of different subunits.

Finally, it is worth noting that while Barbieri et al. (2012) performed whole-exome sequencing of primary PCa samples and found MED12 to be mutated in six out of 111 samples, Stoehr et al. (2013) reported a lack of evidence for MED12 mutations using Sanger sequencing of PCa samples from a small subgroup of patients. Taken together, our findings indicate that MED12 expression clearly plays a role in PCa and is directly implicated in TGF $\beta$ signaling in PCa.

\section{Supplementary data}

This is linked to the online version of the paper at http://dx.doi.org/10.1530/ ERC-14-0171.

\section{Declaration of interest}

The University of Bonn has filed a patent which includes and is not limited to the use of MED12 in prostate cancer, on which S Perner, D Adler, R Menon and $\mathrm{M}$ Braun are co-inventors.

\section{Funding}

The study was supported by a grant from the German Research Foundation (Deutsche Forschungsgemeinschaft (DFG), Emmy-Noether-Program, (PE1179/2-1), the Rudolf-Becker-Foundation, and the Wilhelm-SanderFoundation (2011.077.1), to S Perner, a medical doctoral fellowship grant (BONFOR) of the Medical Faculty of the University of Bonn to A Offermann, the Ferdinand Eisenberger Fellowship of the German Society of Urology (DGU) to I Syring, and the Medical Faculty Heidelberg of the University of Heidelberg to $S$ Duensing.

Author contribution statement

$S$ Perner and D Ädler study concept and approach. S Perner, D Adler, A Offermann, and M Braun designed experiments. A Offermann, R Menon, I Syring, W Vogel, M Braun, M Nowak, R Halbach, and $D$ Adler carried out the experiments. $L$ Bubendorf, C A Rentsch, O Andren, and M Svensson provided tissues. S Perner D Adler, A Offermann, and $M$ Braun analyzed and interpreted data. S Perner, D Adler, and A Offermann wrote manuscript. S Duensing, L Bubendorf, S Biskup, J Kirfel, C Ruiz, O Andren, and $\mathrm{M}$ Svensson revised manuscript.

\section{References}

Barbieri CE, Baca SC, Lawrence MS, Demichelis F, Blattner M, Theurillat JP, White TA, Stojanov P, Van Allen E, Stransky N et al. 2012 Exome

Published by Bioscientifica Ltd. 
sequencing identifies recurrent SPOP, FOXA1 and MED12 mutations in prostate cancer. Nature Genetics 44 685-689. (doi:10.1038/ng.2279)

Benavides MA, Hagen KL, Fang W, Du P, Lin S, Moyer MP, Yang W, Bland KI, Grizzle WE \& Bosland MC 2010 Suppression by L-methionine of cell cycle progression in LNCaP and MCF-7 cells but not benign cells. Anticancer Research 30 1881-1885.

Braun M, Scheble VJ, Menon R, Scharf G, Wilbertz T, Petersen K, Beschorner C, Reischl M, Kuefer R, Schilling D et al. 2011 Relevance of cohort design for studying the frequency of the ERG rearrangement in prostate cancer. Histopathology 58 1028-1036. (doi:10.1111/j.13652559.2011.03862.x)

Cai G, Imasaki T, Takagi Y \& Asturias FJ 2009 Mediator structural conservation and implications for the regulation mechanism. Structure 17 559-567. (doi:10.1016/j.str.2009.01.016)

Castro F, Dirks WG, Fahnrich S, Hotz-Wagenblatt A, Pawlita M \& Schmitt M 2013 High-throughput SNP-based authentication of human cell lines. International Journal of Cancer 132 308-314. (doi:10.1002/ijc.27675)

Chen M, Carkner R \& Buttyan R 2011 The hedgehog/Gli signaling paradigm in prostate cancer. Expert Review of Endocrinology \& Metabolism 6 453-467. (doi:10.1586/eem.11.24)

Cifuentes E, Croxen R, Menon M, Barrack ER \& Reddy GP 2003 Synchronized prostate cancer cells for studying androgen regulated events in cell cycle progression from G1 into S phase. Journal of Cellular Physiology 195 337-345. (doi:10.1002/jcp.10317)

Cipriano SC \& Chen YQ 1998 Insensitivity to growth inhibition by TGF- $\beta 1$ correlates with a lack of inhibition of the CDK2 activity in prostate carcinoma cells. Oncogene 17 1549-1556. (doi:10.1038/sj.onc.1202069)

Doganavsargil B, Simsir A, Boyacioglu H, Cal C \& Hekimgil M 2006 A comparison of p21 and p27 immunoexpression in benign glands, prostatic intraepithelial neoplasia and prostate adenocarcinoma. BJU International 97 644-648. (doi:10.1111/j.1464-410X.2006.06054.x)

Gaspar NJ, Li L, Kapoun AM, Medicherla S, Reddy M, Li G, O’Young G, Quon D, Henson M, Damm DL et al. 2007 Inhibition of transforming growth factor $\beta$ signaling reduces pancreatic adenocarcinoma growth and invasiveness. Molecular Pharmacology 72 152-161. (doi:10.1124/ mol.106.029025)

Hesse M, Raulf A, Pilz GA, Haberlandt C, Klein AM, Jabs R, Zaehres H, Fugemann CJ, Zimmermann K, Trebicka J et al. 2012 Direct visualization of cell division using high-resolution imaging of M-phase of the cell cycle. Nature Communications 3 1076. (doi:10.1038/ ncomms2089)

Huang S, Holzel M, Knijnenburg T, Schlicker A, Roepman P, McDermott U, Garnett M, Grernrum W, Sun C, Prahallad A et al. 2012 MED12 controls the response to multiple cancer drugs through regulation of TGF- $\beta$ receptor signaling. Cell 151 937-950. (doi:10.1016/j.cell.2012.10.035)

Kapoor A, Goldberg MS, Cumberland LK, Ratnakumar K, Segura MF, Emanuel PO, Menendez S, Vardabasso C, Leroy G, Vidal CI et al. 2010 The histone variant macroH2A suppresses melanoma progression through regulation of CDK8. Nature 468 1105-1109. (doi:10.1038/nature09590)

Karan D, Kelly DL, Rizzino A, Lin MF \& Batra SK 2002 Expression profile of differentially-regulated genes during progression of androgen-independent growth in human prostate cancer cells. Carcinogenesis 23 967-975. (doi:10.1093/carcin/23.6.967)

Karavitakis M, Ahmed HU, Abel PD, Hazell S \& Winkler MH 2011 Tumor focality in prostate cancer: implications for focal therapy. Nature Reviews. Clinical Oncology 8 48-55. (doi:10.1038/nrclinonc.2010.190)

Kim S, Xu X, Hecht A \& Boyer TG 2006 Mediator is a transducer of Wnt/ $\beta$-catenin signaling. Journal of Biological Chemistry 281 14066-14075. (doi:10.1074/jbc.M602696200)

Knuesel MT, Meyer KD, Donner AJ, Espinosa JM \& Taatjes DJ 2009 The human CDK8 subcomplex is a histone kinase that requires Med12 for activity and can function independently of mediator. Molecular and Cellular Biology 29 650-661. (doi:10.1128/MCB.00993-08)

Larsson M, Uvell H, Sandstrom J, Ryden P, Selth LA \& Bjorklund S 2013 Functional studies of the yeast med5, med15 and med16 mediator tail subunits. PLOS ONE 8 e73137. (doi:10.1371/journal.pone.0073137)
Lu S, Lee J, Revelo M, Wang X, Lu S \& Dong Z 2007 Smad3 is overexpressed in advanced human prostate cancer and necessary for progressive growth of prostate cancer cells in nude mice. Clinical Cancer Research $\mathbf{1 3}$ 5692-5702. (doi:10.1158/1078-0432.CCR-07-1078)

Mad'arova J, Lukesova M, Hlobilkova A, Strnad M, Vojtesek B, Lenobel R, Hajduch M, Murray PG, Perera S \& Kolar Z 2002 Synthetic inhibitors of CDKs induce different responses in androgen sensitive and androgen insensitive prostatic cancer cell lines. Molecular Pathology 55 227-234. (doi:10.1136/mp.55.4.227)

Makinen N, Mehine M, Tolvanen J, Kaasinen E, Li Y, Lehtonen HJ, Gentile M, Yan J, Enge M, Taipale M et al. 2011 MED12, the mediator complex subunit 12 gene, is mutated at high frequency in uterine leiomyomas. Science 334 252-255. (doi:10.1126/science.1208930)

Malik S \& Roeder RG 2010 The metazoan Mediator co-activator complex as an integrative hub for transcriptional regulation. Nature Reviews. Genetics 11 761-772. (doi:10.1038/nrg2901)

Martin-Caballero J, Flores JM, Garcia-Palencia P, Collado M \& Serrano M 2004 Different cooperating effect of p21 or p27 deficiency in combination with INK4a/ARF deletion in mice. Oncogene $\mathbf{2 3}$ 8231-8237. (doi:10.1038/sj.onc.1207863)

Moore LD, Isayeva T, Siegal GP \& Ponnazhagan S 2008 Silencing of transforming growth factor- $\beta 1$ in situ by RNA interference for breast cancer: implications for proliferation and migration in vitro and metastasis in vivo. Clinical Cancer Research 14 4961-4970. (doi:10.1158/ 1078-0432.CCR-07-4604)

Munoz-Alonso MJ, Acosta JC, Richard C, Delgado MD, Sedivy J \& Leon J 2005 p21 ${ }^{\text {Cip1 } 1}$ and p2 $7^{\text {Kip1 }}$ induce distinct cell cycle effects and differentiation programs in myeloid leukemia cells. Journal of Biological Chemistry 280 18120-18129. (doi:10.1074/jbc.M500758200)

Park BJ, Park JI, Byun DS, Park JH \& Chi SG 2000 Mitogenic conversion of transforming growth factor- $\beta 1$ effect by oncogenic Ha-Ras-induced activation of the mitogen-activated protein kinase signaling pathway in human prostate cancer. Cancer Research 60 3031-3038.

Polyak K, Kato JY, Solomon MJ, Sherr CJ, Massague J, Roberts JM \& Koff A $1994 \mathrm{p} 27^{\mathrm{Kip} 1}$, a cyclin-Cdk inhibitor, links transforming growth factor$\beta$ and contact inhibition to cell cycle arrest. Genes and Development 8 9-22. (doi:10.1101/gad.8.1.9)

Remmele W \& Stegner HE 1987 Recommendation for uniform definition of an immunoreactive score (IRS) for immunohistochemical estrogen receptor detection (ER-ICA) in breast cancer tissue. Pathologe $\mathbf{8}$ 138-140.

Robson CN, Gnanapragasam V, Byrne RL, Collins AT \& Neal DE 1999 Transforming growth factor- $\beta 1$ up-regulates p15, p21 and p27 and blocks cell cycling in G1 in human prostate epithelium. Journal of Endocrinology 160 257-266. (doi:10.1677/joe.0.1600257)

Shaikhibrahim Z, Menon R, Braun M, Offermann A, Queisser A, Boehm D, Vogel W, Ruenauver K, Ruiz C, Zellweger T et al. 2013 MED15, encoding a subunit of the mediator complex, is overexpressed at high frequency in castration-resistant prostate cancer. International Journal of Cancer 135 19-26. (doi:10.1002/ijc.28647)

Sherr CJ \& Roberts JM 1999 CDK inhibitors: positive and negative regulators of G1-phase progression. Genes and Development $\mathbf{1 3}$ 1501-1512. (doi:10.1101/gad.13.12.1501)

Stoehr R, Taubert H, Gaisa NT, Smeets D, Kneitz B, Giedl J, Ruemmele P, Wieland WF, Rau TT \& Hartmann A 2013 Lack of evidence for frequent MED12 p.L1224F mutation in prostate tumours from Caucasian patients. Journal of Pathology 230 453-456. (doi:10.1002/ path.4208)

Tang B, de Castro K, Barnes HE, Parks WT, Stewart L, Bottinger EP, Danielpour D \& Wakefield LM 1999 Loss of responsiveness to transforming growth factor $\beta$ induces malignant transformation of nontumorigenic rat prostate epithelial cells. Cancer Research $\mathbf{5 9}$ 4834-4842.

Van Themsche C, Mathieu I, Parent S \& Asselin E 2007 Transforming growth factor- $\beta 3$ increases the invasiveness of endometrial carcinoma cells through phosphatidylinositol 3-kinase-dependent up-regulation

Published by Bioscientifica Ltd. 
of X-linked inhibitor of apoptosis and protein kinase c-dependent induction of matrix metalloproteinase-9. Journal of Biological Chemistry 282 4794-4802. (doi:10.1074/jbc.M608497200)

Vo BT, Cody B, Cao Y \& Khan SA 2012 Differential role of Sloan-Kettering Institute (Ski) protein in Nodal and transforming growth factor- $\beta$ (TGF- $\beta$ )-induced Smad signaling in prostate cancer cells. Carcinogenesis 33 2054-2064. (doi:10.1093/carcin/bgs252)

Walker L, Millena AC, Strong N \& Khan SA 2013 Expression of TGF $\beta 3$ and its effects on migratory and invasive behavior of prostate cancer cells: involvement of PI3-kinase/AKT signaling pathway. Clinical \& Experimental Metastasis 30 13-23. (doi:10.1007/s10585-012-9494-0) van de Wetering M, Sancho E, Verweij C, de Lau W, Oving I, Hurlstone A, van der Horn K, Batlle E, Coudreuse D, Haramis AP et al. 2002 The $\beta$-catenin/TCF-4 complex imposes a crypt progenitor phenotype on colorectal cancer cells. Cell 111 241-250. (doi:10.1016/S00928674(02)01014-0)

Yardy GW \& Brewster SF 2005 Wnt signalling and prostate cancer. Prostate Cancer and Prostatic Diseases 8 119-126. (doi:10.1038/sj.pcan.4500794)

Zavadil J \& Bottinger EP 2005 TGF- $\beta$ and epithelial-to-mesenchymal transitions. Oncogene 24 5764-5774. (doi:10.1038/sj.onc.1208927)

Zhang Q, Rubenstein JN, Jang TL, Pins M, Javonovic B, Yang X, Kim SJ, Park I \& Lee C 2005 Insensitivity to transforming growth factor- $\beta$ results from promoter methylation of cognate receptors in human prostate cancer cells (LNCaP). Molecular Endocrinology 19 2390-2399. (doi:10. 1210/me.2005-0096)

Zhou H, Kim S, Ishii S \& Boyer TG 2006 Mediator modulates Gli3dependent sonic hedgehog signaling. Molecular and Cellular Biology 26 8667-8682. (doi:10.1128/MCB.00443-06)

Received in final form 11 June 2014

Accepted 16 June 2014

Made available online as an Accepted Preprint

17 June 2014
(C) 2014 Society for Endocrinology Printed in Great Britain
Published by Bioscientifica Ltd. 